\section{Caesarean section and phaeochromocytoma resection in a patient with Von Hippel Lindau disease}

Denise Joffe MD, Ross Robbins MD, Alice Benjamin MD
This report describes the anaesthetic management of a women with a term gestation, Von Hippel Lindau disease (VHLD), and a phaeochromocytoma, scheduled for a combined phaeochromocytoma resection and Caesarean section. Von Hippel Lindau disease is characterized by diffuse haemangioblastomas of the central nervous system (CNS) and viscera. It is also associated with phaeochromocytomas and renal cell carcinomas. Patients frequently have asymptomatic spinal cord and intracranial pathology. The patient and her fetus presented a challenge because of the anaesthetic restrictions imposed by $V H L D$, and her pregnancy. She was also at risk of developing malignant hypertension from the phaeochromocytoma. The patient was not a candidate for regional anaesthesia because of the possibility of spinal cord haemangioblastomas. She had received adrenergic blockade with phentolamine (total $30 \mathrm{mg}$ a day) and propranolol (total $40 \mathrm{mg}$ a day) since the 27th wk of gestation in order to control hypertension secondary to the phaeochromocytoma. General anaesthesia was administered with aggressive management of hypertension with adrenergic blockers (labetalol $1.0 \mathrm{mg} \cdot \mathrm{kg}^{-1}$ and esmolol $0.75 \mathrm{mg} \cdot \mathrm{kg}^{-1}$ ) and sodium nitroprusside $1.5 \mu \mathrm{g} \cdot \mathrm{kg}^{-1}$ (total). Before delivery of the baby, opioids, which could have resulted in a fetus with CNS depression, were avoided. After delivery, opioids (sufen-

\section{Key words}

ANAESTHESIA: obstetrical;

DISEASES: Von Hippel Lindau;

SURGERY: phaeochromocytoma.

From the Departments of Anaesthesia and Obstetrics, McGill University, Royal Victoria Hospital, 687 Pine Avenue West, Montreal, Quebec, H3A 1A1.

Address correspondence to: Dr. D. Joffe, Department of Anaesthesia, The Montreal Children's Hospital, 2300 Tupper

St., Montreal, Quebec H3H 1P3. (514) 934-4641.

Accepted for publication 18th May, 1993. tanil $0.4 \mu \mathrm{g} \cdot \mathrm{kg}^{-I} \cdot \mathrm{hr}^{-1}$ ) were used to limit the use of inhalational anaesthesia which may contribute to uterine atony. Postoperative pain was managed with an intravenous narcotic infusion. Both patients had uneventful postoperative courses.

Cette observation décrit la conduite anesthésique chez une parturiente à terme souffrant de la maladie de Von Hippel Lindau (MVHL) associée à un phéochromocytome, programmée pour une césarienne et une résection simultanée de phéochromocytome. La maladie de Von Hippel Lindau est caractérisée par une hémangioblastomatose diffuse du système nerveux central et des viscères. Elle s'accompagne souvent de phéochrocytomes et de cellules carcinomateuses rénales. Les pathologies spinale et intracrânienne sont souvent silencieuses. La MVHL et la grossesse rendent plus complexe la conduite anesthésique. Au phéochromocytome se greffe aussi un risque d'hypertension maligne. La possibilité dhémangioblastose spinale fait de la malade une mauvaise candidate pour la régionale. A partir de la 27ième semaine de gestation, l'hypertension secondaire au phéochromocytome est contrôlée par une médication antiadrénergique de phentolamine (30 mg par jour) et de propanolol (40 mg par jour). Pendant l'anesthésie générale, avec le même objectif, on administre des bloqueurs adrénergiques (labétalol $1,0 \mathrm{mg} \cdot \mathrm{kg}^{-1}$ et esmolol $0,75 \mathrm{mg} \cdot \mathrm{kg}^{-1}$ ) avec du nitroprussiate de soude $1,5 \mu \mathrm{g} \cdot \mathrm{kg}^{-1}$ (dose totale). Avant la naissance, les opiacés sont évités dans le but de prévenir la dépression foetale. Après la naissance, du sufentanil 0,4 $\mu \mathrm{g} \cdot \mathrm{kg}^{-1} \cdot \mathrm{h}^{-1}$ permet de limiter la concentration dinhalatoire pour prévenir l'atonie utérine. La douleur postopératoire est traitée avec une perfusion morphinique. La mère et l'enfant récupèrent sans complications.

Von Hippel Lindau disease (VHLD) is a familial disease transmitted by an autosomal dominant gene with variable penetrance. It is characterized by haemangioblastomas of the retina, central nervous system (CNS) and viscera. ${ }^{1}$ Patients are usually referred for surgery for cerebellar, spinal and retinal involvement. Although histologically 
benign, these tumours can cause serious symptoms secondary to pressure on surrounding structures or haemorrhage. These patients are also at increased risk for phaeochromocytomas and renal cell carcinomas. ${ }^{1-3}$

\section{Case report}

A 35-yr-old $\mathrm{G}_{2} \mathrm{P}_{0} \mathrm{~A}_{1}$ woman with a history of VHLD since age 26 presented at $22 \mathrm{wk}$ gestation for routine obstetrical evaluation. The patient had had three previous surgical resections for occipital, parietal and cervical haemangioblastomas. She had mild dysaethesias on the left side from the chest down.

For the past ten years the patient had been followed in a VHLD clinic for the development of retinoblastomas, renal cell carcinomas, phaeochromocytomas and ganglioblastomas. She was investigated for phaeochromocytomas with yearly urine measurements of catecholemines and their metabolites. The patient was informed that a recent urine screening revealed evidence of a phaeochromocytoma but, at the time, the patient was not aware of her pregnancy. Her urine measurements were as follows: urine normetanephrine $12966 \mathrm{nmol} \cdot \mathrm{d}^{-1}$ (normal, 502-2531 $\left.\mathrm{nmol} \cdot \mathrm{d}^{-1}\right)$, metanephrine $342 \mathrm{nmol} \cdot \mathrm{d}^{-1}$ (normal, 281-1841 $\mathrm{nmol} \cdot \mathrm{d}^{-1}$ ), norepinephrine 2623 $\mathrm{nmol} \cdot \mathrm{d}^{-1}$ (normal, $<591 \mathrm{nmol} \cdot \mathrm{d}^{-1}$ ) epinephrine 84 $\mathrm{nmol} \cdot \mathrm{d}^{-1}$ (normal, $<136 \mathrm{nmol} \cdot \mathrm{d}^{-1}$ ), dopamine 3425 $\mathrm{nmol} \cdot \mathrm{d}^{-1}$ (normal, <2531), vanillylmandelic acid 3.4 $\mu \mathrm{mol} \cdot \mathrm{mmol}^{-1}$ creatinine (normal, $0-4 \mu \mathrm{mol} \cdot \mathrm{mmol}^{-1}$ creatinine). She subsequently had an ultrasound examination which demonstrated the presence of a $2.7 \times 3.2$ $\mathrm{cm}^{2}$ right adrenal mass.

The patient was examined every week in the prenatal clinic by an obstetrician and an endocrinologist for clinical or laboratory evidence of a hypercatecholaminergic state, e.g., evidence of anxiety, diaphoresis, vomiting, headaches, tremulousness, hypertension, palpitations, convulsions, dysrhythmias, dehydration and hyperglycaemia. ${ }^{4,5}$ She was admitted at $271 / 2$ wk gestation with a diagnosis of hypertension. Blood pressure (BP) on admission was $150 / 100 \mathrm{mmHg}$ (MAP $116 \mathrm{mmHg}$ ) and heart rate was 85 beats $\cdot \min ^{-1}$. She was treated with phenoxybenzamine $10 \mathrm{mg}$ po bid. Propranolol $10 \mathrm{mg}$ po bid was added because the patient developed symptomatic tachycardia. The haemodynamic goals were to maintain $\mathrm{BP}<140 / 90 \mathrm{mmHg}$, without producing symptomatic postural hypotension and to maintain the heart rate $<100$ beats $\cdot \mathrm{min}^{-1}$. She was discharged 17 days later on a regimen of phenoxybenzamine $20 \mathrm{mg}$ po qam and $10 \mathrm{mg}$ po qpm, and propranolol $10 \mathrm{mg}$ po qid, which produced acceptable BP and HR control.

The obstetrician and endocrinologist felt it was unsafe for the patient to go into labour because of reports of the development of hypertensive crisis during labour in patients with phaeochromocytomas. ${ }^{4-7}$ She was scheduled for Caesarean section $(\mathrm{C} / \mathrm{S})$ at $38 \mathrm{~s} / 7$ wk when the lecithin-sphingomyelin ratio $(>2.5)$ indicated fetal maturity.

There were no preoperative systolic BP's $>140 \mathrm{mmHg}$ or heart rates (HR) $>100$ beats $\cdot \mathrm{min}^{-1}$. Preoperative ECG showed normal sinus rhythm, no ectopy, haemoglobin $90 \mathrm{~g} \cdot \mathrm{L}^{-1}$, haematocrit $34 \%$, glucose 4.3 $\mathrm{mmol} \cdot \mathrm{L}^{-1}$ and the plasma electrolyte concentrations were normal.

Before surgery she received propranolol $20 \mathrm{mg} p o$, ranitidine $50 \mathrm{mg}$ po and sodium citrate $30 \mathrm{ml}$. The endocrinologist recommended against administration of phenoxybenzamine because of its long half life (greater than $24 \mathrm{hr}){ }^{8}$ The intraoperative course of a phaeochromocytoma resection is occasionally complicated by severe haemodynamic instability characterized by hypertension as well as hypotension, which characteristically occurs after removal of the catecholamine secreating tumour. ${ }^{9}$ It was felt that these haemodynamic fluctuations could be more easily managed with short-acting intravenous agents.

In the operating room, the patient was given oxygen by face mask, placed with a wedge under her right side, and had pulse oximetry, a noninvasive blood pressure cuff, ECG and fetal heart rate monitoring applied. A 16-gauge peripheral $i$, a 20 -gauge arterial line, and an 8.5 French right internal jugular introducer and a pulmonary artery catheter were placed using sterile technique and local anaesthesia.

During placement of invasive monitoring, the patient's BP did not exceed $160 / 100 \mathrm{mmHg}$ (mean arterial pressure (MAP) $115 \mathrm{mmHg}$ ), and her $\mathrm{HR}$ was $<80$ beats $\cdot \mathrm{min}^{-1}$ despite anxiety. Labetalol in increments of 10 and $20 \mathrm{mg}$ (total $100 \mathrm{mg}$ ) was titrated to decrease MAP to approximately $100 \mathrm{mmHg}$ during this time.

Before induction of anaesthesia the BP was 140/90 $\mathrm{mmHg}$ (MAP 106), HR 80 beats $\cdot \mathrm{min}^{-1}$, PCWP 17 $\mathrm{mmHg}$, PAP $36 / 24 \mathrm{mmHg}$, CVP $12 \mathrm{mmHg}$, CO 7.3 $\mathrm{L} \cdot \min ^{-1}, \mathrm{Cl} 3.7 \mathrm{~L} \cdot \mathrm{min}^{-1} \cdot \mathrm{m}^{2}$. Small doses of nitroprusside (NTP) $0.5 \mu \mathrm{g} \cdot \mathrm{kg}^{-1}$ were titrated to bring the MAP to $100 \mathrm{mmHg}$ (total $100 \mu \mathrm{g}$ ). After pre-oxygenation, anaesthesia was induced with thiopentone 4 $\mathrm{mg} \cdot \mathrm{kg}^{-1}$, lidocaine $1 \mathrm{mg} \cdot \mathrm{kg}^{-1}$, bolus doses, of esmolol $30 \mathrm{mg}$ (total $0.75 \mathrm{mg} \cdot \mathrm{kg}^{-1}$ ). Succinylcholine 1.5 $\mathrm{mg} \cdot \mathrm{kg}^{-1}$, was given to facilitate tracheal intubation after which the BP was $190 / 120 \mathrm{mmHg}$ and the HR 100 beats $\cdot \min ^{-1}$. An additional $1 \mu \mathrm{g} \cdot \mathrm{kg}^{-1}$ nitroprusside decreased the blood pressure to preinduction levels. Anaesthesia was maintained with $\mathrm{N}_{2} \mathrm{O} 50 \%$ in $\mathrm{O}_{2}$ and $0.5 \%$ inspired isoflurane until delivery. Induction to delivery 
time was four minutes, and uterine incision to delivery time was $70 \mathrm{sec}$

Apgar scores were 7 at one minute and 8 at five minutes. After delivery, the patient was given sufentanil 0.75 $\mu \mathrm{g} \cdot \mathrm{kg}^{-1}$, midazolam $2 \mathrm{mg}, \mathrm{N}_{2} \mathrm{O} 70 \%$ in $\mathrm{O}_{2}$, inspired isoflurane of $0.5 \%$ and a syntocinon infusion (20 units $\cdot \mathrm{L}^{-1} 0.9 \%$ saline) at $100 \mathrm{ml} \cdot \mathrm{hr}^{-1}$. After the $\mathrm{C} /$ $\mathrm{S}$ was completed, the patient was repositioned and prepared for a right lateral flank incision. Anaesthesia was maintained with sufentanil $\left(0.4 \mu \mathrm{g} \cdot \mathrm{kg}^{-1} \cdot \mathrm{hr}^{-1}\right)$, and lowdose isoflurane. Muscle relaxation was maintained with vecuronium.

Vasodilators were required once after induction. A brief infusion of NTP at $0.25 \mu \mathrm{g} \cdot \mathrm{kg}^{-1} \cdot \mathrm{min}^{-1}$ was given during the phaeochromocytoma resection to maintain MAP $<120 \mathrm{mmHg}$. During the combined procedures, the systolic BP was never $>180 \mathrm{mmHg}$ even with adrenal or aortic massage. Vasopressors were not required after resection of the phaeochromocytoma. Blood glucose remained at $7-9 \mathrm{mmol} \cdot \mathbf{L}^{-1}$. Blood loss was estimated at $1200 \mathrm{ml}$ and four liters of Ringer's Lactate were given. The urine output was $300 \mathrm{ml}$. At the end of surgery $(3.5 \mathrm{hr})$ residual muscle relaxation was reversed and the trachea was extubated. The patient was transferred to the intensive care unit (ICU) with an $i v$ fentanyl infusion at $100 \mu \mathrm{g} \cdot \mathrm{kg}^{-1}$. The postoperative haematocrit was $33 \%$ and blood glucose values remained within the normal range. Admission in the ICU was uneventful and she was discharged to the general surgical ward the following morning with a patient-controlled analgesia pump. Both mother and baby had uncomplicated postoperative courses and were discharged home the following week. The pathology report described a well-circumscribed phaeochromocytoma. Unfortunately, the patient developed a renal cell carcinoma one year later which is scheduled for resection.

\footnotetext{
Discussion

This case presents unique anaesthetic and obstetrical challenges. The patient presented in the second trimester of pregnancy with a phaeochromocytoma, a potentially lifethreatening disease capable of causing malignant hypertension. She had a history of multiple CNS haemangioblastomas and was at risk of having asymptomatic intracranial and spinal lesions. Obstetrical considerations included the optimal timing for phaeochromocytoma resection and $\mathrm{C} / \mathrm{S}$ and the use of preoperative adrenergic blockade. Anaesthetic considerations included contraindications to regional anaesthesia and the difficulty of optimizing haemodynamic control in a patient with a phaeochromocytoma and possible intracranial mass. Unknown changes in placental perfusion secondary to chronically elevated catecholamine levels and the requirement for
}

intravenous vasodilators with possible adverse fetal effects were also potential problems.

The anaesthetic management of phaeochromocytomas, in particular phaeochromocytomas in pregnancy, is controversial. ${ }^{4,5,10}$ Until recently, recommendations for phaeochromocytoma resection in pregnant patients depended on the fetus's gestational age. Phaeochromocytomas detected in the first trimester were resected and the pregnancies terminated. In the second trimester they were resected without termination of the pregnancy and in the third trimester a combined phaeochromocytoma resection and $\mathrm{C} / \mathrm{S}$ were performed. ${ }^{4,7}$ This aggressive approach to early phaeochromocytoma resection was the result of the high maternal $(58 \%)$ and fetal mortality $(56 \%)$ in patients in whom the diagnosis was made unexpectedly postpartum. ${ }^{5}$

Since the introduction of effective pharmacological adrenergic blockade, the optimal timing for surgery is debatable. It would be ideal to allow the pregnancy to be carried to term if it incurred minimal risk to the mother and fetus. The lack of supporting evidence for the effectiveness of treatment as well as possible iatrogenic effects of long-term treatment have caused some to recommend immediate removal of the tumour with presurgical alpha adrenergic blockade when the diagnosis is made in the first or early second trimester. ${ }^{3}$ In one survery of phaeochromocytomas in pregnancy, ${ }^{11}$ fetal and maternal mortality were $0(n=1)$ with early tumour excision and delayed $C / S$ in a patient who had received preoperative alpha adrenergic blockade. Fetal loss and maternal mortality were also $0(n=2)$ when combined term $\mathrm{C} / \mathrm{S}$ and tumour excision were performed in patients with preoperative adrenergic blockade. Fetal loss was $33 \%$ with no maternal mortality $(n=3)$ with term delivery and delayed tumour excision. (Patients whose tumour could not be localized at the time of $\mathrm{C} / \mathrm{S}$ had delayed tumour excisions.) Patients received alpha blockade for 84-91 days without any apparent fetal effects. Although the number of patients followed is too small to make conclusive recommendations, if the patient responds to treatment, and if the fetus is doing well, it seems reasonable to consider a combined phaeochromocytoma resection and $\mathrm{C} / \mathrm{S}$ at term.

It is interesting to note that our patient's BP did not require treatment until $27 \mathrm{wk}$ of gestation and at that time very small doses of phenoxybenzamine were sufficient despite remarkably high levels of circulating catecholamines. This is consistent with the course of phaeochromocytomas in some pregnant women. ${ }^{6}$ More than half of the severe symptoms and maternal deaths occur in the postpartum period, within $72 \mathrm{hr}$ of delivery.

Although phaeochromocytomas have been resected using epidural anaesthesia, ${ }^{9}$ spinal cord involvement is 
estimated to occur in $28-100 \%$ of VHLD patients. ${ }^{1,12}$ The latter figure comes from an autopsy of ten patients who died of complications of VHLD (cerebral bleeds). All ten patients were found to have spinal cord involvement. The lesions are usually asymptomatic, single, and cervicothoracic in origin, although they may involve the lumbosacral cord and cauda equina. ${ }^{13}$ They are usually located in the pia or intramedullary cord posteriorly. In half, meningeal varicosities are present. ${ }^{14}$ Haemangioblastomas have also been found in nerve roots and in vertebrae. The intramedullary spinal haemangioblastomas are associated with a syringomyelia in $60-80 \%$ of cases. $1,13,15,16$

The only previous report in the anaesthesia literature describing a $\mathrm{C} / \mathrm{S}$ in a woman with VHLD successfully used an $\mathrm{L}_{2}-\mathrm{L}_{3}$ epidural anaesthetic. ${ }^{17}$ The authors stated that they chose an epidural technique because general anaesthesia presented a "theoretical" risk of a hypertensive crisis in a patient with the potential for an asymptomatic CNS haemangioblastoma. They stated that they also avoided a spinal technique because of the possibility of spinal cord haemangioblastomas. We feel that an epidural technique is also contraindicated if spinal anaesthesia is being avoided on grounds of potential spinal cord involvement. There is the possibility of direct injury to the cord or its nerves and vessels by the epidural needle or catheter.

Cerebellar tumours occur in about $60 \%$ of patients with VHLD ${ }^{2}$ and brain stem tumours in $14-50 \%$. Accessible lesions are removed surgically. ${ }^{2,15}$ There is a 3-10\% recurrence rate after an apparent complete excision. CAT scan and angiograms are the imaging techniques of choice, although they have missed lesions. ${ }^{15}$ We were particularly concerned with the possibility of occult intracerebral lesions in this woman and the risk of a hypertensive-induced cerebrovascular accident.

During line placement we titrated labetalol in anticipation of laryngoscopy, and surgical stimulation, as long as the fetus and the patient's haemodynamic state allowed. We elected to avoide opioids to control hypertension until the baby was delivered, so as not to contribute to fetal depression. Instead, small boluses of nitroprusside and esmolol were used as adjuvant therapy. We wanted to minimize the use of vasoactive agents with long half lives. Labetalol has the longest half life of the agents (four hours) vs nitroprusside and esmolol (minutes). ${ }^{8}$ These medications have been used during pregnancy without significant effects on the fetus. We used two different adrenergic blockers in order to decrease the dose of each. Labetalol in doses of $1.0 \mathrm{mg} \cdot \mathrm{kg}^{-1}$ has been used safely ${ }^{18}$ whereas esmolol has been implicated in causing fetal distress in patients with decreased placental perfusion. ${ }^{19}$
The haemodynamic goals during induction were based on an attempt to maintain placental blood flow without risking severe hypertension in a patient with the possibility of an intracranial mass. We chose the supranormal MAP based on what is generally recommended in severe preeclamptics as preinduction haemodynamic goals in order to preserve placental blood flow. ${ }^{20}$ Although it was unlikely that this patient's placenta had the ischaemic vascular changes characteristic of preeclampsia we considered that her hypertension and chronic elevated catecholamine levels may have caused some changes in placental blood flow and autoregulation. ${ }^{4}$ We also wanted to maintain a safety margin of placental perfusion in case she responded precipitously to the antihypertensives.

During the phaeochromocytoma resection inhalational anaesthesia was limited and an opioid, nitrous oxide, and benzodiazepine maintenance was chosen in order to decrease the risk of uterine atony. The use of ergotamines or prostaglandins to treat uterine atony could have precipitated severe hypertension.

In summary, the management of a patient with VHLD for a combined phaeochromocytoma resection and $\mathrm{C} /$ $\mathrm{S}$ is presented. The possibility of asymptomatic spinal cord and CNS haemangiomas led us to avoid regional anaesthesia. Reports of hypertensive crisis in parturients with phaeochromocytomas required that we carefully control hypertension. The patient had preoperative antihypertensive therapy with adrenergic blockers. Anaesthetic goals were to maintain aggressive intraoperative blood pressure control with short-acting vasoactive agents and adrenergic blockers, and, if possible, to avoid using large doses of opioids and benzodiazepines (to control hypertension) prior to delivery of the baby. We also avoided high concentrations of inhalational agents after the $\mathrm{C} / \mathrm{S}$ to avoid contributing to uterine atony.

\section{References}

1 Cobb CA, Youmans JR. Sarcomas and neoplasms of blood. In: Youmans JR (Ed.). Neurological Surgery, 3rd edition. Philadelphia: Saunders Co., 1990; 3153-8.

2 Nibbelink DW, Peters BH, McCormick WF. On the association of pheochromocytoma and cerebellar hemangioblastoma. Neurology 1969; 19: 455-9.

3 Martuza RI, Rouleau G. Genetic aspects of neurosurgical problems. In: Youmans JR (Ed.). Neurological Surgery, 3rd edition. Philadelphia: Saunders Co., 1990: 1075-6.

4 Schenker JG, Granat $M$. Phaeochromocytoma and pregnancy - an updated appraisal. Aust N Z J. Obstet Gynaecol 1982; 22: 1-10.

5 Schenker JG, Chowders I. Pheochromocytoma and pregnancy. Obstet Gynecol Surv 1971; 26: 739-46.

6 Ellison GT, Mansberger JA, Mansberger AR Jr. Malignant recurrent phaeochromocytoma during preg- 
nancy: case report and review of the literature. Surgery 1988; 103: 484-9.

7 Fudge TL, McKinnon WMP, Geary WL. Current surgical management of pheochromocytoma during pregnancy. Arch Surg 1980; 115: 1224-5.

8 Hoffman BB, Lefkowitz RJ. Adrenergic receptor antagonists. In: Goodman LS, Gilman A, Rall TW, Nies AS, Taylor $\mathbf{P}$ (Eds.). The Pharmacological Basis of Therapeutics, 8th ed. New York: Pergamon Press, 1990; 221-43.

9 Cousins MJ, Rubin RB. The intraoperative management of phaeochromocytoma with total epidural sympathetic blockade. Br J Anaesth 1974; 46: 78-81.

10 Lyons CW. Colmorgen GHC. Medical management of phaeochromocytoma in pregnancy. Obstet Gynecol 1988; 72: $450-1$.

11 Burgess G III. Alpha blockade and surgical intervention of phaeochromocytoma during pregnancy. Obstet Gynecol 1979; 53: 266-70.

12 Levin PM. Multiple hereditary hemangioblastomas of the nervous system. Archives of Neurology and Psychiatry 1935; 36: 384-91.

13 Otenasek FJ, Silver ML. Spinal hemangioma (hemangioblastoma) in Lindau's disease. J Neurosurg 1961; 18: 295-300.

14 Browne TR, Adams RD, Robertson GH. Hemangioblastomas of the spinal cord. Arch Neurol 1976; 33: 435-41.

15 Rawe SE, Van Gilder JC, Rothman SLG. Radiographic diagnostic evaluation and surgical treatment of multiple cerebellar, brain stem and spinal cord hemangioblastomas. Surg Neurol 1978; 9: 337-41.

16 Yasargil MG, Antic J, Laciga $R$, de Preux J, Fideler $R W$, Boone $S C$. The microsurgical removal of intramedullary spinal hemangioblastomas. Report of twelve cases and a review of the literature. Surg Neurol 1976; 6: 141-8.

17 Matthews AJ, Halshaw J. Epidural anaesthesia in von Hippel-Lindau disease. Anaesthesia 1986; 41: 853-5.

18 Eisenach JC, Mandell G, Dewan DM. Maternal and fetal effects of labetalol in pregnant ewes. Anesthesiology 1991; 74: 292-7.

19 Ducey JP, Knape KG. Maternal esmolol administration resulting in fetal distress and cesarean section in a term pregnancy. Anesthesiology 1992; 77: 829-32.

20 James FM III. Pregnancy induced hypertension. In: James FM III, Wheeler AS, Dewan DM (Eds.). Obstetric Anesthesia: The Complicated Patient, 2nd edition. Philadelphia: F.A. Davis Co., 1988; 417-8. 